\title{
A Young Male with a Non-ST Elevation Myocardial Infarction and Polycythemia Vera
}

Firdous F. Ghori ( $\nabla$ dr.firdouseghori@gmail.com )

Hamad Medical Corporation

Ahmed A. Elyas

Hamad Medical Corporation

Dina S. Soliman

Hamad Medical Corporation

Alia M. Amer

Hamad Medical Corporation

Abulrahman Arabi

Hamad Medical Corporation

Mohamed A. Yassin

Hamad Medical Corporation

\section{Research Article}

Keywords: Polycythemia rubra vera, coronary artery disease, myocardial infarction, drug eluting stents or DES.

Posted Date: June 7th, 2021

DOI: https://doi.org/10.21203/rs.3.rs-420929/v1

License: (c) (i) This work is licensed under a Creative Commons Attribution 4.0 International License.

Read Full License 


\section{Abstract}

Polycythemia Vera (PV) is a clonal myeloproliferative disease characterized by an erythroid dominant trilineage proliferation of hematopoietic precursor cells. Acute coronary syndrome is known to occur in patients with PV. However, there are very rare reported cases of myocardial infarction upon the initial presentation of PV. We present such a case of a 37 years old male, with no known cardiovascular risk factors, who had an initial presentation of NSTEMI treated with drug eluting stent (DES). Later investigations revealed a diagnosis of Polycythemia Vera. Treatment strategies for MI in cases of myeloproliferative disease lacking clear guidance, further studies are needed in this matter.

\section{Introduction}

The myeloproliferative neoplasms (MPNs), previously termed the myeloproliferative disorders, are characterized by the clonal proliferation of one or more hematopoietic cell lineages, predominantly in the bone marrow, but sometimes in the liver and spleen (1). Myeloproliferative neoplasia (MPN) can be classified into Philadelphia chromosome-negative and Philadelphia chromosome positive. Chronic myeloid leukemia (CML) is a clonal hematologic neoplasm characterized by the presence of the BCR$A B L 1$ rearrangement, resulting in a constitutively active tyrosine kinase (2). The Philadelphia chromosome-negative (Ph-) classical myeloproliferative neoplasms include essential thrombocythemia [ET], polycythemia vera [PV], and myelofibrosis [MF] (3). MPN are usually sporadic, but rarely familial cases are seen (4).

Myocardial infarction (MI) is well known to be associated with PV. In one study, MI was seen in about $11.4 \%$ of patients with PV (5) . However, there are few reported cases of myocardial infarction preceding the initial diagnosis of PV (6-15). Myeloproliferative diseases including essential thrombocythemia (ET) and PV are well known to cause arterial and venous thrombosis, but only a few studies has explored the occurrence of myocardial infarction (MI ) in cases of PV and ET (5), (16). Even though there are several recommendations for treatment of cases of PV and ET which presents with MI or acute coronary syndrome (ACS), there is no clear guideline consensus built on evidence-based medicine. Most experts recommend the use of standard therapy of dual anti platelets post MI in addition to cytoreductive therapy (17), (18), (19). However, little is known about the interaction of the cytoreductive therapy with newer generations of anti-platelets and drug eluting stents (DES). anagrelide is recommended as a second-line therapy MI associated with myeloproliferative disease tend to be ST elevation myocardial infarction (STEMI) due to acute thrombotic occlusion of coronaries, cases with non-ST elevations myocardial infarction (NSTEMI) are rarely reported in this context. Here we report such a case of a young male without cardiovascular risk factors with an initial presentation of NSTEMI, in whom further work up revealed PV.

\section{Case}


A 37-year-old Egyptian male presented to the emergency with a history of chest pain for three days. The pain was on \& off, radiating to the left arm and associated with sweating and there were no other complaints. History was negative for any cardiovascular risk factors including hypertension, diabetes mellitus, dyslipidemia and family history of cardiac disease. He was a non-smoker and denied use of any recreational drugs. No past medical illnesses apart from appendicitis for which he underwent Laparoscopic Appendectomy in 2018.

Upon presentation, he was afebrile and vitally stable with a BP 140/90 and oxygen saturation of $99 \%$. Physical examination was unremarkable. Initial ECG showed sinus rhythm with biphasic T wave inversion in V3 and V4 leads Figure(1). The following ECG revealed transient ST segment elevation in leads V2, V3 and V4 which quickly resolved without any evolving changes Figure(2).

His initial laboratory investigations showed alarming thrombocytosis and high hemoglobin with platelets of $877 \times 10^{\wedge 3} / \mathrm{ml}$ hemoglobin of $17 \mathrm{gm} / \mathrm{dl}$, hematocrit of $50 \%$ and leukocytes of $10.4 \times 10^{\wedge 3} / \mathrm{ml}$. Renal parameters, liver function tests, lipid profile and coagulation profile were normal. His total cholesterol was $4.1 \mathrm{mmol} / \mathrm{L}$ and $\mathrm{LDL}$ cholesterol of $1.6 \mathrm{mmol} / \mathrm{L}$.

Serial troponin T tests were mildly elevated with a value of 47,45 with a maximum value of $54 \mathrm{ng} / \mathrm{L}$. Echocardiogram revealed mildly reduced LV systolic function (EF $44 \%$ ) with akinetic apical segments, and grade 1 diastolic dysfunction. Patient was diagnosed as Non-ST elevation myocardial infarction (NSTEMI) based on the typical history of chest pain, pattern of changes on ECG and the extent of troponin rise which was not very high as usually seen in cases of ST elevation myocardial infarction (STEMI). He was treated with aspirin and clopidogrel, at first loading dose of $300 \mathrm{mg}$ each and then maintenance dose. He also received enoxaparin anticoagulation with beta blockers and statins. Coronary angiogram revealed obstructive single vessel disease with severe atheromatous eccentric lesion in mid left anterior descending artery (LAD) Figure $(3, \underline{A})$. PCl was done to the mid LAD with drug-eluting stent (DES) Xience Sierra Figure $(\underline{3}, \underline{B})$. After PCl he was kept on aspirin $100 \mathrm{mg}$ once daily and switched to ticagrelor twice daily in addition to statin and beta blockers.

After resolution of the acute cardiac incident, platelets and hemoglobin remained high. Hence work up was done to investigate for Polycythemia Vera. ABG revealed no hypoxia, Erythropoietin level was 3.24 $\mathrm{mlU} / \mathrm{ml}(2.5-18 \mathrm{mlU} / \mathrm{ml})$, and JAK2 V617 mutation came back positive. Cytogenetics for BCR ABL were negative. Bone marrow biopsy was done to confirm Polycythemia Vera Figure(4). The diagnosis of nonST elevation MI was made initially, followed by the diagnosis of Polycythemia vera. For the NSTEMI a drug eluting stent was placed, and he was kept on dual antiplatelet therapy. For the Polycythemia vera, cytoreduction with Interferon was started.

Peripheral blood shows moderate thrombocytosis, mild neutrophilia and within normal hemoglobin level and hematocrit percentage. Bone marrow (BM) aspirate smear shows trilineage hematopoiesis with $2 \%$ blasts. 
BM biopsy was small and showed mild hypercellularity ( 75-85\%) with active trilineage hyperplasia (panmyelosis). There is megakaryocytic proliferation, displaying evident anisocytosis and pleomorphism, occur solitary and in few small loose/dense clusters. The bone marrow showed some dilated vascular sinuses.

No increase in CD34-positive blasts and no significant increase in reticulin fibers.

FISH analysis using $B C R / A B L 1$ is negative.

Molecular genetics revealed Positive JAK2 V617F missense mutation.

Overall findings were consistent with a myeloproliferative neoplasm; the mild hypercellularity with marginal increase in hemoglobin/hematocrit (on previous CBC reading); would favor the diagnosis of early stage of Polycythemia Vera.

\section{Discussion}

Polycythemia Vera (PV) is a clonal myeloproliferative disease characterized by an erythroid dominant trilineage proliferation of hematopoietic precursor cells. Diagnostic criteria according to the WHO 2016 classification are as follows:

\section{Major criteria:}

1. Hemoglobin > $16.5 \mathrm{~g} / \mathrm{dL}$ (men), Hemoglobin > $16.0 \mathrm{~g} / \mathrm{dL}$ (women) or Hematocrit > 49\% (men), Hematocrit $>48 \%$ (women) or increased red cell mass $(\mathrm{RCM})^{\mathrm{c}}$

2.BM biopsy showing hypercellularity for age with trilineage growth (panmyelosis) including prominent erythroid, granulocytic and megakaryocytic proliferation with pleomorphic, mature megakaryocytes (differences in size).

3. Presence of JAK2 V617F or JAK2 exon 12 mutation.

\section{Minor Criteria:}

1.Subnormal serum Erythropoietin level

Diagnosis requires meeting all 3 major criteria, or 2 major and 1 minor criteria

Thromboembolic disease is common in PV. It was reported in $41 \%$ of PV patients in a large retrospective Italian cohort of 1213 patients and found to affect both arterial and venous vascular trees with higher percentage in arterial tree (20).

Myocardial infarction in patients on PV can occur due to several mechanisms including thrombotic occlusion (seen in STEMI cases) and arteriosclerotic changes (more common in NSTEMI) (15).Some rare 
mechanism were reported like marked intimal proliferation which was reported in an autopsy of a 30 years old female who died of Ml as first presentation of PV (21). The data analysis of myocardial infarction with myeloproliferative disease is somewhat scarce and mostly comes from case reports. There are only a few studies that have explored the extent of MI in these cases. Among these; Rossi has followed 149 PV patient for 10 years and found that $11 \%$ of them suffered an MI , one sixth (17\%) of those patients were younger than 40 years old (5). The occurrence of acute $\mathrm{MI}$ in patients with PV or ET was analyzed in a retrospective study (2016) of 263 patients revealed $14 \mathrm{Ml}$ events (5.3\%), majority of the events occurred during the first year after diagnosis. Contrary to the expected, most of the cases were NSTEMI, 10 cases versus 4 cases of STEMI(16). Majority of MI patients in PV setting are reported in the literature as STEMI. Limited information exists about the association of NSTEMI to myeloproliferative neoplasms, despite it has been reported in literature (22-26), when present, it tends to be associated with multiple atherosclerotic risk factors. Up to our knowledge, our case is the first young patient without cardiovascular risk factors who presented with NSTEMI in PV literature, however, there are few cases reported with ET (22-26). His presentation was subacute with only minimal rise in troponins and dynamic ECG changes that concur with the diagnosis of NSTEMI, he had transient ST elevation which does not fit with the pattern of STEMI. His angiogram also showed focal narrowing rather than thrombus occlusion which suggest either arteriosclerosis or intimal proliferation.

PV may be discovered incidentally during routine blood work and may present with symptoms of thrombosis or bleeding which adding a challenge when selecting anti-platelet therapy. The new antiplatelet were not explored thoroughly in the setting of PV, however, one case report showed a better response to dual therapy of ticagrelor and aspirin in a patient who had seven prior cardiovascular events on clopidogrel monotherapy (27). With the ongoing advance of coronary intervention for the past decade, management strategies have changed, these changes are not reflected well in PV literature, particularly the introduction of newer antiplatelet like ticagrelor and prasugrel which lower stent thrombosis risk compared to clopidogrel. Also, the use of newer generations of DES like Zotarolimus and Everolimuseluting stents, which were found to have less chances of thrombosis compared to the older DES generations which were used in the early 2000s. One case report documented using thrombectomy, phlebotomy in acute state, intracoronary eptifibatide and double-dose IV unfractionated heparin for thrombus removal and prevention of further coronary thrombosis (28). anagrelide is recommended as a second-DES was reported only in few patients in PV literature, although we believe this number is under presented with the wide use of DES nowadays. Despite the thrombotic tendency of patients of PV; still there is no unified management strategy for treatment of these cases when presenting as an $\mathrm{Ml}$ or ACS.line therapy

\section{Conclusion}

PV diagnosis should be considered among the causes of $\mathrm{Ml}$ in young age. Treatment strategies for $\mathrm{Ml}$ in cases of myeloproliferative disease lacking clear guidance, further studies are needed in this matter. Coronary interventionists need to be aware of potential complications due to hyper viscosity syndrome in 
cases of myeloproliferative neoplasms. STEMI and NSTEMI can occur in PV cases at a younger age and needs to be explored in larger studies.

\section{Declarations}

\section{Funding:}

Qatar National Library for funding of manuscript publication.

Conflicts of interest/Competing interests:

All authors declare no conflicts of interest.

\section{Ethics approval:}

Ethical approval by Medical Research Center - Hamad Medical corporation in Qatar with protocol ID MRC-04-21-263.

Consent to participate:

The patient was consented for the case report.

\section{Consent for publication:}

The patient was consented for publication.

\section{Availability of data and material:}

All data are available if required.

Code availability:

Not applicable.

\section{Authors' contributions:}

F.F. Ghori, A. Elyas -drafting the manuscript, approved final draft.

D. Soliman, A. Amer -pathology provided slides, approved final draft.

A. Arabi - coronary angiogram slides, approved final draft.

M. Yassin - case report concept, mentoring, approved final draft.

\section{References}


1. Passamonti F, Mora B, Maffioli M. New molecular genetics in the diagnosis and treatment of myeloproliferative neoplasms. Current opinion in hematology. 2016 Mar 1;23(2):137-43.

2. Turkina A, Wang J, Mathews V, Saydam G, Jung CW, Al Hashmi HH, Yassin M, Le Clanche S, Miljkovic D, Slader C, Hughes TP. TARGET: a survey of real-world management of chronic myeloid leukaemia across 33 countries. British Journal of Haematology. 2020 Sep;190(6):869-76.

3. Yassin MA, Taher A, Mathews V, Hou HA, Shamsi T, Tuğlular TF, Xiao Z, Kim SJ, Depei W, Li J, Rippin G. MERGE: a multinational, multicenter observational registry for myeloproliferative neoplasms in Asia, including Middle East, Turkey, and Algeria. Cancer medicine. 2020 Jul;9(13):4512-26.

4. Al-Dewik N, Ben-Omran T, Zayed H, Trujillano D, Kishore S, Rolfs A, Yassin MA. Clinical Exome Sequencing unravels new disease-causing mutations in the myeloproliferative neoplasms: a pilot study in patients from the state of Qatar. Gene. 2019 Mar 20;689:34-42.

5. Rossi C, Randi ML, Zerbinati P, Rinaldi V, Girolami A. Acute coronary disease in essential thrombocythemia and polycythemia vera. Journal of internal medicine. 1998 Jul;243(7):49-53.

6. Gouri A, Yakhlef A, Dekaken A, Bentorki AA. Acute myocardial infarction revealing a polycythemia vera. InAnnales de biologie clinique 2012 Jul 1 (Vol. 70, No. 4, pp. 489-491).

7. Wu CF, Armstrong GP, Henderson RA, Ruygrok PN. Polycythaemia vera presenting as ST-elevation myocardial infarction. Heart, Lung and Circulation. 2005 Mar 1;14(1):51-3.

8. Wirth L. Myocardial infarction as the initial manifestation of polycythemia vera. Mil Med. 1960;125:544

9. VACCA JB, THOMA GE. Myocardial infarction as the initial manifestation of polycythemia vera. AMA archives of internal medicine. 1959 Jun 1;103(6):974-7.

10. 10 Tekin M, Gökaslan S, Diker E, Aydoğdu S. Development of acute coronary syndrome in three patients with essential thrombocythemia or polycythemia vera. Turk Kardiyoloji Dernegi Arsivi: Turk Kardiyoloji Derneginin Yayin Organidir. 2008 Jan 1;36(1):35-8.

11. Goethals P, Evrard S, Dubois C. Recurrent coronary stent thrombosis. Acta cardiologica. 2000 Dec 1;55(6):371-3.]

12. Chan AW, Drobac M, Sternberg L. The management of acute myocardial infarction in a patient with polycythemia rubra vera during the thrombolytic era-does it make a difference?. The Canadian journal of cardiology. 1997 Jan 1;13(1):59-63.

13. Rykov VA, Letunova ON. Polycythemia vera, complicated by myocardial infarction. Arkhiv patologii. 1995 May 1;57(3):73-4.

14. Skribnik Ela., Oteva E.A. Rare types of myocardial infarction in young patients. Klin Med (Mosk) 1991;69(11):32-35.

15. Bahbahani $\mathrm{H}$, Aljenaee K, Bella A. Polycythemia vera presenting as acute myocardial infarction: An unusual presentation. Journal of the Saudi Heart Association. 2015 Jan 1;27(1):57-60.

16. Pósfai É, Marton I, Borbényi Z, Nemes A. Myocardial infarction as a thrombotic complication of essential thrombocythemia and polycythemia vera. Anatolian journal of cardiology. 2016 
Jun;16(6):397.

17. Benedek I, Lázár E, Sándor-Kéri J, Bíró Sz, Jakab Sz, Jr. Benedek I. Acute Coronary Syndromes in Patients with Hematological Disorders. Journal of Cardiovascular Emergencies. 2016;2:159-168. DOI: $10.1515 /$ jce-2016-0024.

18. Landolfi R, Marchioli R, Kutti J, Gisslinger H, Tognoni G, Patrono C, Barbui T. Efficacy and safety of low-dose aspirin in polycythemia vera. New England Journal of Medicine. 2004 Jan 8;350(2):114-24.

19. Tortorella G, Calzolari M, Tieghi A, Muià N, Piccin A, Gugliotta L. Acute coronary syndrome (ACS) in patients with essential thrombocytemia (ET). What is the best treatment? International journal of cardiology. 2016 Jan 15;203:225-7.

20. Policitemia GI. Polycythemia vera: the natural history of 1213 patients followed for 20 years. Annals of Internal Medicine. 1995 Nov 1;123(9):656-64.

21. Hermanns B, Handt S, Kindler J, FÜzesi L. Coronary vasculopathy in polycythemia vera. Pathology \& Oncology Research. 1998 Mar;4(1):37-9.

22. Nazha B, Garcia G, Kandov R, Odaimi M. Calreticulin mutated essential thrombocythemia presenting as acute coronary syndrome. Case reports in hematology. 2015 Apr 29;2015.

23. Bošnjak I, Selthofer-Relatić K, Periša V, Steiner R. Therapeutic dilemmas in the treatment of acute coronary syndrome as manifestation of essential thrombocythaemia. Journal of cardiology cases. 2013 Nov 1;8(5):168-71.

24. Lim YH, Lee YY, Kim JH, Shin J, Lee JU, Kim KS, Kim SK, Kim JH, Lim HK. Development of acute myocardial infarction in a young female patient with essential thrombocythemia treated with anagrelide: a case report. The Korean journal of hematology. 2010 Jun;45(2):136.

25. Arampatzis S, Stefanidis I, Liakopoulos V, Raio L, Surbek D, Mohaupt MG. Postpartal recurrent nonST elevation myocardial infarction in essential thrombocythaemia: case report and review of the literature. Thrombosis journal. 2010 Dec;8(1):1-6.

26. Cheng CW, Hung MJ. Coronary spasm-related acute myocardial infarction in a patient with essential thrombocythemia. World journal of cardiology. 2011 Aug 26;3(8):278.

27. Pedersen OH, Larsen ML, Kristensen SD, Hvas AM, Grove EL. Recurrent cardiovascular events despite antiplatelet therapy in a patient with polycythemia vera and accelerated platelet turnover. The American journal of case reports. 2017;18:945.

28. Davis MI, Courtney BK, Cohen G, Poon S, Madan M. Polycythemia Vera Presenting as Cardiac Arrest: Novel Management Strategies. Case reports in cardiology. 2019 Jan 22;2019.

\section{Figures}




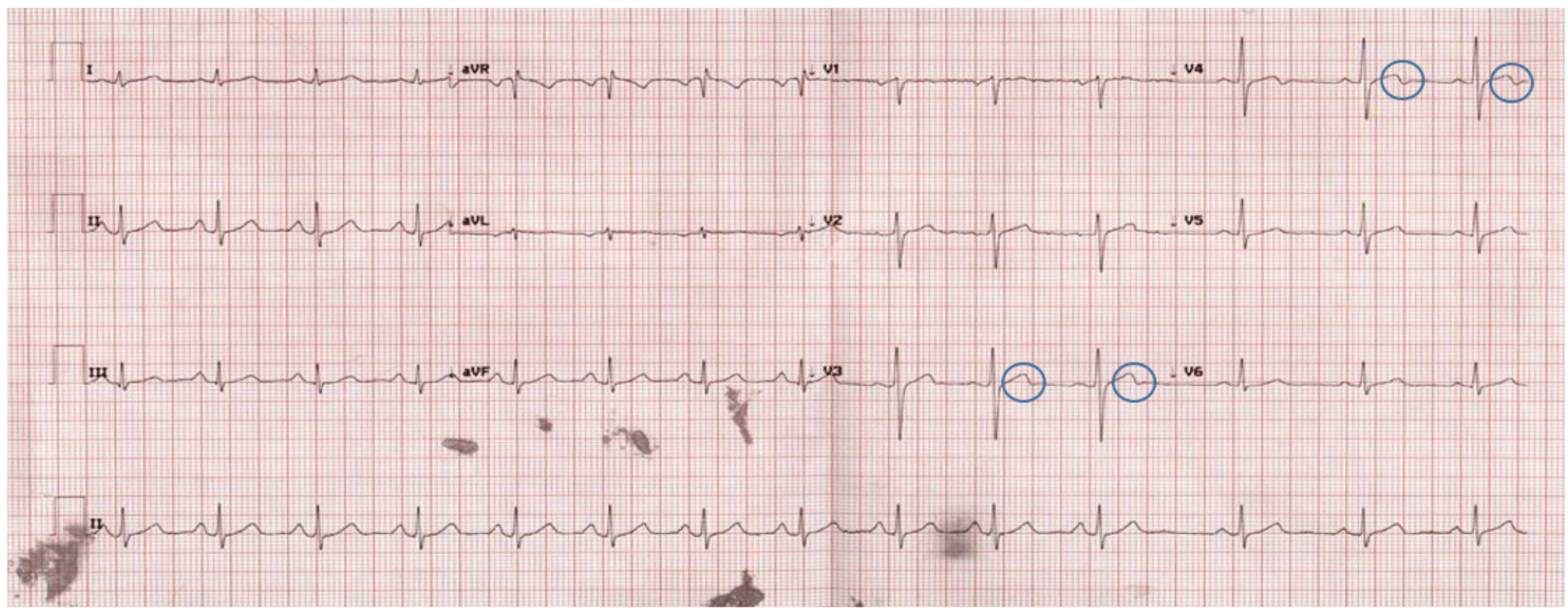

Figure 1

ECG on day 1 showing biphasic T wave in leads V3 -V4 (circles)

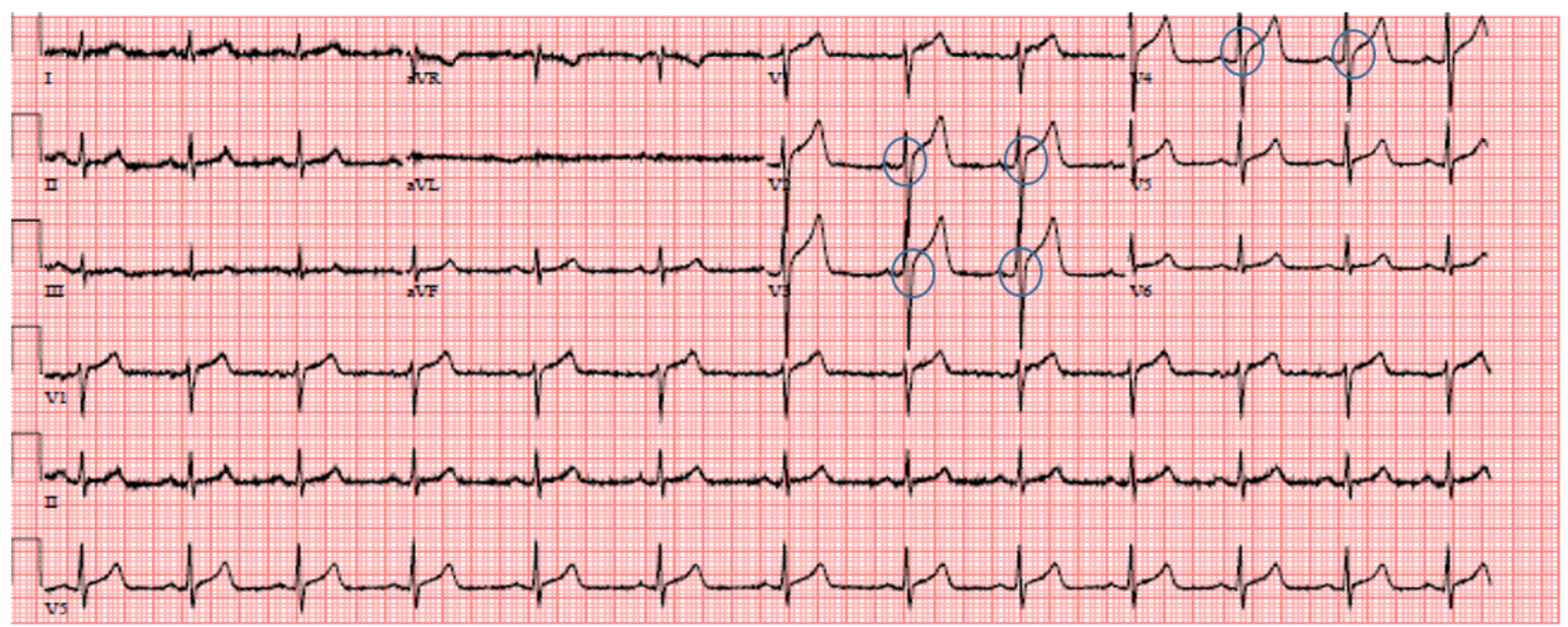

Figure 2

ECG on day 2 which has showed ST elevation in V2- V4 (circles), these changes were transient for minutes and the subsequent ECG s were totally normal. 

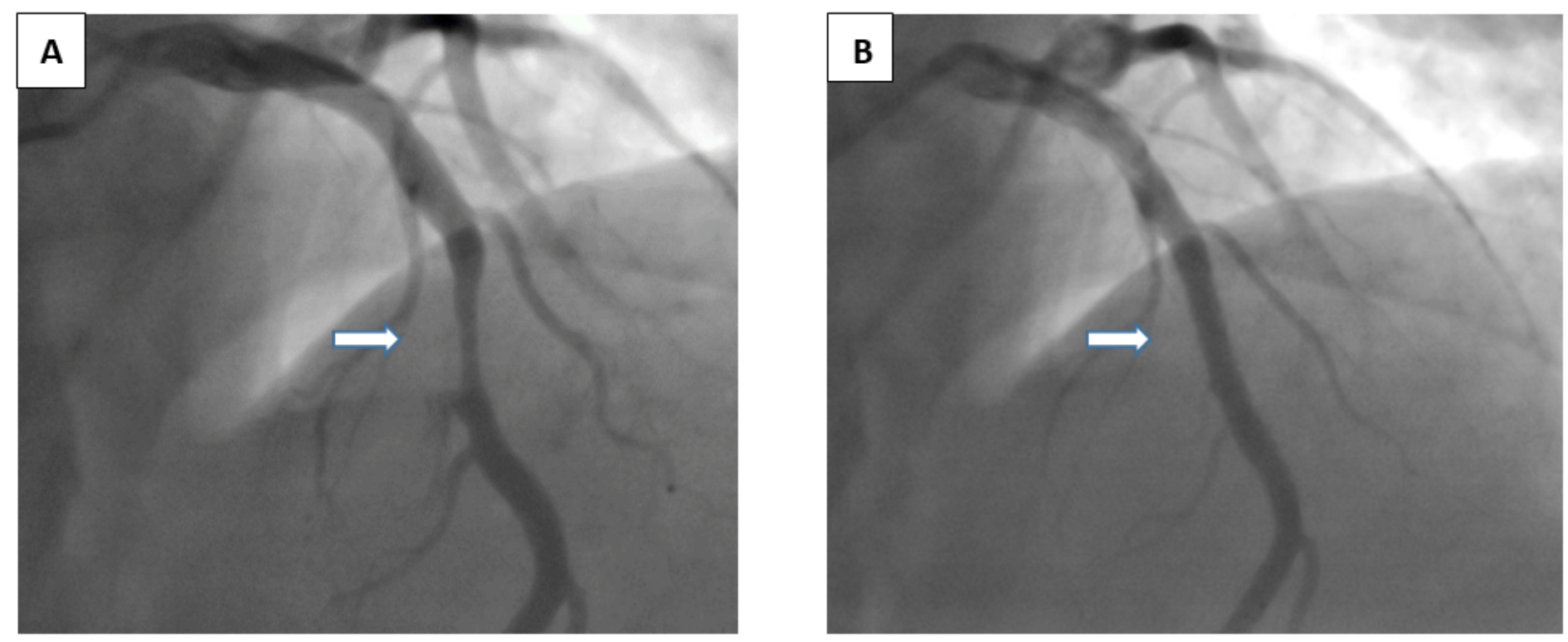

\section{Figure 3}

Coronary Angiogram showing RAO cranial projection showing $80 \%$ lesion (arrows) in mid LAD before (A) and after (B) stenting with DES Xience Sierra stent. 


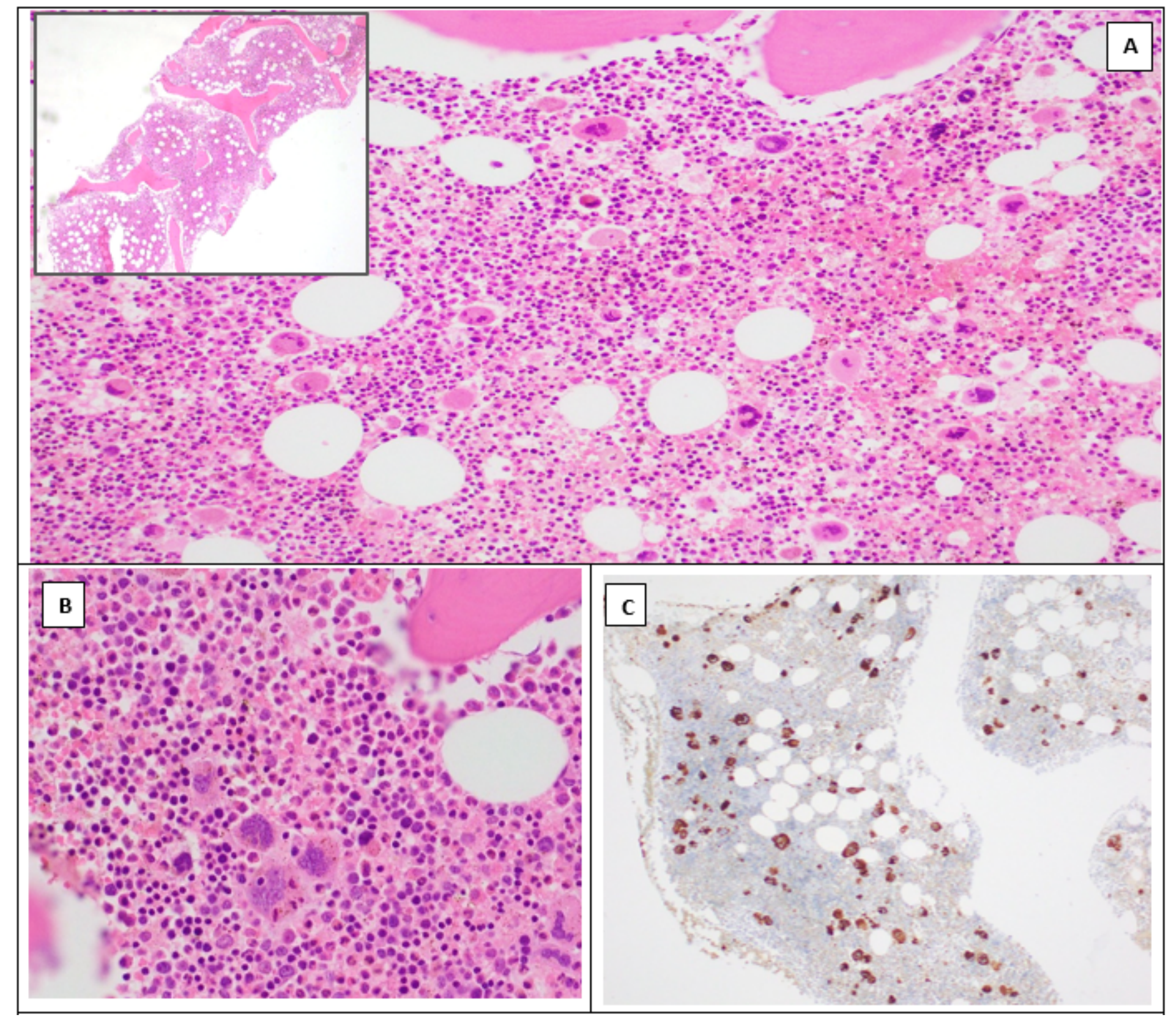

\section{Figure 4}

Bone marrow (BM) biopsy H\&E (10x; insert 4x) reflects mildly hypercellular bone marrow with active trilineage hyperplasia (panmyelosis) and prominent erythropoiesis $(A)$. There is marked megakaryocytic proliferation displaying evident anisocytosis and pleomorphism, occur solitary and in few small loose/dense clusters (BM biopsy H\&E (40x) (B), highlighted by vWF immunostains (C). 